\title{
HUBUNGAN PENGETAHUAN TENTANG HIV/AIDS DENGAN PEMANFAATAN PELAYANAN VCT DI PUSKESMAS GEDONGTENGEN YOGYAKARTA
}

\section{THE RELATION OF KNOWLEDGE OF HIV / AIDS WITH THE USE OF VCT SERVICE IN PUSKESMAS GEDONGTENGEN YOGYAKARTA}

\author{
Luluk Rosida $^{1}$, Devi Pratiwi ${ }^{2}$ \\ ${ }^{1,2}$ Program Studi DIV Bidan Pendidik Universitas ‘ Aisyiyah Yogyakarta \\ Email : rosidalulu@gmail.com
}

\begin{abstract}
ABSTRAK
Kelompok usia reproduktif tersebut menyumbang lebih dari 70\% kasus AIDS, namun dalam SDKI 2012 pada wanita 15-49 tahun dan pria kawin umur 15-54 tahun yang pernah mendengar tentang HIV/AIDS, tidak sesuai dengan tingkat pengetahuan tentang cara mengurangi risiko tertular HIVIAIDS. Tujuan dari penelitian ini adalah untuk mengetahui hubungan antara pengetahuan tentang HIVIAIDS dengan pemanfaatan layanan VCT. Desain penelitian ini adalah penelitian survei analitik, pendekatan yang digunakan adalah cross sectional. Teknik sampel yang digunakan accidental sampling sebanyak 30 responden datang ke layanan VCT Puskesmas Gedongtengen. Teknik analisa data menggunakan uji chi square. Penelitian ini menunjukkan berdasarkan hasil Uji chi square didapatkan hasil bahwa terdapat hubungan antara pengetahuan dan pemanfaatan pelayanan VCT di Puskesmas Gedongtengen. Berdasarkan hasil dapat diambil kesimpulan yaitu terdapat hubungan antara pengetahuan dan pemanfaatan pelayanan VCT di Puskesmas Gedongtengen. Deteksi dini diri sendiri terhadap infeksi HIV dianjurkan demi terciptanya masyarakat sehat. Terutama saat akan menikah dan merencanakan kehamilan dengan mendatangi puskesmas yang menyediakan pelayanan VCT.
\end{abstract}

Kata Kunci Pengetahuan, HIV AIDS, VCT

\section{ABSTRACT}

This reproductive age group accounts for more than 70\% of AIDS cases, but in SDKI 2012 in women 15-49 years and married men aged 15-54 years who have heard about HIV / AIDS, do not match the level of knowledge on how to reduce the risk of contracting HIV / AIDS. The purpose of this study was to determine the relationship between knowledge about HIV / AIDS and the utilization of VCT services. The design of this research is analytic survey research, the approach used is cross sectional. The sample technique used accidental sampling as many as 30 respondents came to the VCT service of Gedongtengen Puskesmas. Data analysis technique using chi square test. This study shows that based on the results of chi square test showed that there is a relationship between knowledge and utilization of VCT services in Gedongtengen Puskesmas. Based on the results can be concluded that there is a relationship between knowledge and use of VCT services in Gedongtengen Puskesmas. Early self-detection of HIV infection is recommended for the creation of a healthy society. Especially when getting married and planning a pregnancy by visiting a health center that provides VCT services.

Keywords Knowledge, HIV AIDS, VCT

\section{PENDAHULUAN}

Indonesia merupakan negara urutan ke lima di Asia yang paling berisiko HIV AIDS. Menurut Survei Demografi Kesehatan Indonesia (SDKI) tahun 2012 kasus HIV positif di Indonesia pada adalah 21.511 meningkat 2,3\% dari tahun 2011. Dan kasus kumulatif AIDS pada tahun 2012 adalah 42.887 dengan 5.686 kasus baru. Sedangkan jumlah kematian akibat AIDS sebesar 1,5 juta yang terdiri dari 1,3 juta dewasa (lebih dari 15 tahun) dan sisanya anak-anak kurang dari 15 tahun (Profil PP dan PL, 2012).

Remaja Angka kejadian HIV/AIDS di Provinsi Daerah Istimewa Yogyakarta tahun 2014 sebesar 2.933 dengan kejadian tertinggi di kota Yogyakarta 714 kasus, disusul oleh Kabupaten Sleman 574 kasus dan Kabupaten Bantul 506 kasus (KPA Provinsi DaerahIstimewaYogyakarta,2014). Pelaporan dari Direktorat Jendral PP dan PLKemenkes RI dalam Profil Kesehatan 
Indonesia tahun 2014 bahwa cara penularan AIDS terbesar adalah heteroseksual 81,3\%, homoseksual $5,1 \%$ dan diikuti oleh penasun atau IDU sebesar 3,3\%. Cara penularan heteroseksual yang meningkat pada tahun 2014 dibandingkan dengan tahun 2012 (77,75\%) membuka peluang lebih lebar kepada laki-laki maupun perempuan bahwa keduanya memiliki risiko penularan yang besar.

Salah satu program upaya pengendalian HIV dan AIDS sektor kesehatan adalah tes dan konseling HIV. Tes dan konseling HIV terdapat dua pendekatan yaitu tes HIV atas inisiatif pemberi layanan kesehatan dan konseling yang disingkat TIPK atau Provider initiated tes and counselling/PITC dan konseling dan tes HIV secara sukarela (KTS) atau Voluntary Counselling and Testing/VCT. Mulai tahun 2006, model utama layanan tes HIV adalah VCT. Pendekatan tersebut semata mengandalkan keaktifan klien dalam mencari layanan tes HIV di fasilitas kesehatan ataupun layanan tes HIV berbasis masyarakat. Namun ternyata cakupan dari layanan

VCT tersebut terbatas karena masih adanya ketakutan akan stigma dan diskriminasi serta kebanyakan orang tidak merasa dirinya berisiko tertular HIV meskipun di daerah atau di kelompok prevalensi tinggi (Kemenkes, 2013).

Program VCT merupakan proses konseling dan pemeriksaan HIV yang bertujuan agar seseorang mengetahui kondisi kesehatan klien sejak dini, serta dapat mengantisipasi kemungkinan terburuk terhadap dirinya apabila hasil pemeriksaan positif. VCT juga dapat dimanfaatkan untuk mendapatkan informasi mengenai HIV atau membantu seseorang mencari pelayanan dan bantuan yang sesuai (Melaju MT dan Alene GD, 2012). VCT adalah pemeriksaan yang terpercaya antara klien dan petugas kesehatan, setelah klien memberikan informed consent agarmemberikan klien hasil yang akurat. VCT terdiri dari konseling pretes, konseling postes, dan konseling lanjutan, yang disediakan di tempat pelayanan VCT.

Kota Yogyakarta dengan tingkat HIV paling tinggi di Provinsi DIY Yogyakarta telah menyediakan 15 layanan VCT yang dapat diakses oleh masyarakat, salah satunya di Puskesmas Gedong tengen. Pencapaian VCT di Puskesmas Gedong tengen tahun 2015 sebanyak 770 pada usia subur dengan rincian 467 laki-laki dan 303 wanita. Hal ini dapat dipengaruhi oleh faktor ketidaktahuan tentang layanan VCT, takut akan stigma, dan keyakinan bahwa HIV tidak bisa disembuhkan maka tes HIV tidak diperlukan (Apanga, Paschal A dkk, 2015).Menurut Teklehaimanot dkk tahun 2016 mengemukakan hasil penelitiannya tentang pemanfaatan VCT yang dipengaruhi oleh berbagai factor salh satunya, pengetahuan.

\section{METODE PENELITIAN}

Penelitian ini adalah penelitian survei analitik menggunakan pendekatan cross sectional. Populasi dalam penelitian ini seluruh klien yang melakukan pemeriksaan VCT di Puskesmas Gedong Tengen. Dalam penelitian ini teknik pengambilan sampel yang digunakan adalah accidental sampling. Besar sampel yang digunakan adalah 30 subjek sebagaimana teori Fraenkel dan Wallen dalam Sulistyaningsih(2011) bahwa besar sampel untuk penelitian korelasional minimum yang disarankan adalah 30 subjek. Alat pengumpulan data yang digunakan adalah kuesioner. Bentuk kuesioner menggunakan pertanyaan tertutup (close ended). Analisis data menggunakan analisis univariat dan analisis bivariat yaitu uji chi square.

\section{HASIL DAN PEMBAHASAN}

Puskesmas Gedongtengen Yogyakarta merupakan salah satu dari Puskesmas yang memberikan pelayanan tes HIV/AIDS sukarela dan sebagai tempat rujukan untuk pelayanan tes HIV/AIDS sukarela di Yogyakarta. Konselor tes HIV/AIDS sukarela sebanyak 3 orang (1 perawat dan 2 dokter) yang sudah lulus pelatihan tes HIV/AIDS sukarela dan 1 bidan yang sudah 
mengikuti pelatihan PMTCT. Mobile VCT sudah pernah dilakukan oleh Puskesmas ini sesuai dengan permintaan dari komunitas. Promosi kesehatan yang sudah dilakukan puskesmas ini diantaranya adalah melalui $\mathrm{TV}$, radio, leaflet, koran, dan penyuluhan langsung secara personal. Pelayanan tes HIV/AIDS sukarela bisa didapatkan masyarakat setiap hari pada jam kerja puskesmas.

\section{Gambaran Karakteristik Responden}

Karakteristik responden klien VCT berdasarkan pengetahuan, pendidikan, usia, pekerjaan, jenis kelamin,dan jarak tempat tinggal dapat dilihat pada tabel 4.1 berikut ini

Tabel 1 Distribusi Frekuensi Karakteristik

Responden Berdasarkan Pendidikan, Usia dan Jenis Kelamin di Puskesmas Gedongtengen Yogyakarta

\begin{tabular}{cccc}
\hline No & $\begin{array}{c}\text { Karakteristik } \\
\text { Responden }\end{array}$ & F & $\%$ \\
\hline 1 & Usia & & \\
& Dewasa & 27 & $90 \%$ \\
& Remaja & 3 & $10 \%$ \\
& Total & 30 & $100 \%$ \\
2 & Jenis Kelamin & & \\
Laki-laki & 11 & $36,7 \%$ \\
& Perempuan & 19 & $63,3 \%$ \\
3 & Total & 30 & $100 \%$ \\
& Pendidikan & & \\
& Tinggi & 28 & $93,7 \%$ \\
& Rendah & 2 & $6,3 \%$ \\
& Total & 30 & $100 \%$ \\
\hline
\end{tabular}

Pada tabel 1 menunjukkan bahwa usia responden terbanyak adalah dewasa (usia $\geq 18$ tahun) sebanyak 27 orang $(90 \%)$ dan remaja 3 orang $(10 \%)$. Untuk jenis kelamin paling banyak responden perempuan sebanyak 19 orang (63\%), dan laki-laki sebanyak 11 orang $(37 \%)$ klien VCT terbanyak memiliki pendidikan tinggi yaitu 28 orang $(93 \%)$ sedangkan yang memiliki pendidikan rendah 2 orang (7\%).

\section{Gambaran \\ pengetahuan \\ tentang \\ HIV/AIDS}

Tabel 2 Distribusi Frekuensi Pengetahuan

$$
\text { tentang HIV/AIDS di }
$$

Puskesmas Gedongtengen Yogyakarta

\begin{tabular}{ccc}
\hline Pengetahuan & Persentase & Frekuensi \\
\hline Tahu & $80 \%$ & 24 \\
Tidak Tahu & $20 \%$ & 6 \\
Total & $\mathbf{1 0 0 \%}$ & $\mathbf{3 0}$ \\
\hline
\end{tabular}

Pada tabel 2 menunjukkan bahwa pengetahuan responden terbanyak adalah pada kategori tahu sebanyak 24 orang $(80 \%)$ dan tidak tahu sebanyak 6 orang $(20 \%)$.

Pengetahuan merupakan hasil dari tahu, dan ini terjadi setelah orang melakukan pengindraan terhadap suatu objek tertentu. Pengindraan terjadi melalui pancaindra manusia, yakni indra penglihatan, pendengaran, penciuman, rasa, dan raba. Pengetahuan merupakan domain yang sangat penting dalam membentuk tindakan seseorang (Notoatmodjo, 2014).

Pendidikan adalah salah satu faktor yang berkaitan dengan pengetahuan. Pendidikan yang semakin tinggi maka seseorang akan mudah menerima dan menyesuaikan diri dengan hal-hal baru (Apriyanti, 2014). Hasil penelitian menunjukkan rata rata pendidikan responden berada pada kategori pendidikan tinggi yaitu 28 orang (93\%) sedangkan yang memiliki pendidikan rendah 2 orang $(7 \%)$. Hasil penelitian ini sesuai dengan penelitian Teklehaimanot dkk (2016) menemukan dalam hasil penelitiannya ba6hwa orang dengan pendidikan yang lebih baik akan lebih bersedia datang memeriksakan status HIV-nya pada fasilitas pelayanan kesehatan.

\section{Gambaran Pemanfaatan Fasilitas VCT}

Tabel 3 Distribusi Frekuensi Pengetahuan tentang HIV/AIDS di Puskesmas Gedongtengen Yogyakarta

\begin{tabular}{ccc}
\hline Pemanfaatan Fasilitas & Frekuensi & Persentase \\
VCT & & \\
\hline Memanfaatkan & 22 & $73,3 \%$ \\
Tidak Memanfaatkan & 8 & $26,7 \%$ \\
Total & $\mathbf{3 0}$ & $\mathbf{1 0 0} \%$ \\
\hline
\end{tabular}

Pada tabel 3 menunjukkan bahwa terdapat $22(73,3 \%)$ responden yang memanfaatkan 
pelayanan VCT dan terdapat $8(26,7 \%)$ responden yang tidak memanfaatkan pelayanan VCT.

VCT adalah pemeriksaan yang terpercaya antara klien dan petugas kesehatan, setelah klien memberikan informed consent agarmemberikan klien hasil yang akurat. VCT terdiri dari konseling pretes, konseling postes, dan konseling lanjutan, yang disediakan di tempat pelayanan VCT. Testing HIV dilakukan secara sukarela tanpa paksaan dan tekanan, segera setelah klien memahami berbagai keuntungan, konsekuensi, dan risiko (Depkes, 2006).

Usia dapat menjadi faktor yang memengaruhi pemanfaatan VCT sesuai Teori Anderson dalam Notoatmodjo (2010) bahwa usia mempengaruhi pelayanan kesehatan. Dewasa muda melakukan tes agar mengetahui status HIV-nya sebagai persiapan pernikahan (Moyo, 2009). Hasil penelitian menunjukkan bahwa usia responden terbanyak adalah dewasa (usia $\geq 18$ tahun) sebanyak 27 orang $(90 \%)$ dan remaja 3 orang (10\%). Penelitian Taklehaimanot dkk tahun 2016 menunjukkan proporsi yang pernah melakukan tes lebih tinggi pada remaja, yang tanpa diketahu sebabnya adalah pemuda dengan risiko penularan HIV tinggi. Dalam penelitian Tasa dkk (2016) menemukan hasil bahwa usia tidak berhubungan dengan pemanfaatan fasilitas pelayanan VCT

\section{Hasil uji Chi square Pengetahuan tentang HIV dan VCT dengan Pemanfaatan Layanan VCT di Puskesmas Gedongtengen Yogyakarta}

Tabel 4 Hasil Uji Chi Square Pengetahuan tentang HIV dan VCT dengan Pemanfaatan Layanan VCT di Puskesmas Gedongtengen Yogyakarta

\begin{tabular}{cccccc}
\hline $\begin{array}{c}\text { Pengetah } \\
\text { uan }\end{array}$ & \multicolumn{4}{l}{ Pemanfaatan Fasilitas VCT } \\
& Memanfaatkan & $\begin{array}{c}\text { Tidak } \\
\text { Memanf } \\
\text { aatkan } \\
\text { \%o }\end{array}$ & $\begin{array}{c}\boldsymbol{p} \text { v } \\
\text { value }\end{array}$ \\
\hline Tahu & 21 & 87,5 & 3 & 12,5 & 0,002 \\
Tidak Tahu & 1 & 16,7 & 5 & 83,3 & \\
\hline
\end{tabular}

Hasil uji statistik menggunakan uji chi square pada variabel pengetahuan menunjukkan nilai $p$. value sebesar $0,002<$ $\alpha(0,05)$, sehingga Ho dalam penelitian ini ditolak. Hal ini menunjukkan bahwa hipotesis pertama dapat dibuktikan yaitu ada hubungan antara pengetahuan tentang HIV dan VCT dengan pemanfaatan layanan VCT di Puskesmas Gedongtengen Kota Yogyakarta.

Pengetahuan tentang HIV dan VCT responden pada saat penelitian dapat berhubungan dengan pemanfaatan layanan VCT dikarenakan dengan pengetahuan yang baik akan menyebabkan seseorang menyadari betapa pentingnya status kesehatannya untuk mencegah penularan yang mungkin terjadi. Orang dengan pengetahuan yang baik akan lebih cenderung memanfaatakan layanan kesehatan yang tersedia untuk memastikan bahwa kesehatannya dalam keadaan baik dan jika ada masalah dengan kesehatannya akan segera dilakukan pencegahan dan pengobatan sesegera mungkin.

Hasil penelitian ini sesuai dengan penelitian Moyo (2009) yang menunjukkan hasil pengetahuan tentang HIV/AIDS yang baik dan terdapat dukungan serta perawatan jika hasilnya positif akan menyebabkan seseorang tersebut mencari fasilitas pelayanan VCT. responden yang tahu mengenai HIV dan VCT akan mempengaruhi orang tersebut untuk mencari tahu status HIV nya sehingga ia memanfaatkan fasilitas pelayanan VCT yang tersedia.

Notoatmodjo (2010) menyatakan bahwa pengetahuan merupakan domain yang sangat penting untuk terbentuknya tindakan seseorang (overt behavior), perilaku yang didasari oleh pengetahuan akan lebih langgeng daripada perilaku yang tanpa didasari pengetahuan.

\section{SIMPULAN}

Berdasarkan hasil penelitian Pengetahuan responden terbanyak adalah pada kategori tahu sebanyak 24 orang (80\%) dan tidak tahu sebanyak 6 orang (20\%). Pemanfaatan pelayanan VCT menunjukkan bahwa 
terdapat 22(73,3\%) responden yang memanfaatkan pelayanan VCT dan terdapat $8 \quad(26,7 \%)$ responden yang tidak memanfaatkan pelayanan VCT. Terdapat hubungan antara pengetahuan dengan pemanfaatan layanan VCT di Puskesmas Gedongtengen Kota Yogyakarta dari nilai $p$. value $0,002<\alpha(0,05)$

\section{DAFTAR PUSTAKA}

Apanga, P. A., Robert Akparibo and John K. Awoonor Williams. 2015. Factors

Influencing Uptake Of Voluntary Counselling And Testing Services For HIV/AIDS in the Lower Manya KroboMunicipality (LMKM) in the Eastern Regionof Ghana: a Crosssectional HouseholdSurvey. Journal of Health, Populati $n$ and Nutrition. 32 (23)

BKKBN, Badan Pusat Statistik dan Kementerian Kesehatan. 2013. Survei
DemografiKesehatan Indonesia 2012. Jakarta

Burhan, R. 2013. Pemanfaatan Pelayanan Kesehatan oleh Perempuan Terinfeksi HIV/AIDS. Jurnal Kesmas Nasional, 8 (1): 33-38.

Depkes RI. 2006. Pedoman Pelayanan Konseling dan Testing HIV/AIDS Secara Sukarela (Voluntary Counselling and Testing). Ditjen PP \& PL, Jakarta

Teklehaimanot, H. D., Awash Teklehaimanot, Mekonnen Yohannes, and Dawit Biratu. 2016. Factors Influencing the Uptake of Voluntary HIV Counselingand Testing in RuralEthiopia: a Cross Sectional study. BMC Public Health.16 (239) 